\title{
Toxic shock syndrome complicated with symmetrical peripheral gangrene after liposuction and fat transfer: a case report and literature review
}

\author{
Zhiwan Liu ${ }^{1 \dagger}$, Wenjun Zhang ${ }^{1 \dagger}$, Boyu Zhang ${ }^{2 \dagger}$, Linhao $\mathrm{Ma}^{2}$, Feng Zhou ${ }^{3}$, Zheyuan Hu${ }^{1}$, Xiang Jie ${ }^{1}$,
} Hong Gao ${ }^{1}$ and Xiaohai Zhu ${ }^{1 *}$ (1)

\begin{abstract}
Background: Liposuction is one of the most commonly performed aesthetic procedures. Toxic shock syndrome(TSS) is a rare, life-threatening complication. The incidence rate of TSS is very low in the plastic surgery field, especially after liposuction and fat transfer.

Case presentation: A 23-year-old female patient was transferred to our emergency department from an aesthetic clinic with sepsis shock features after received liposuction and fat transfer. The patient underwent TSS, disseminated intravascular coagulation(DIC), multiple organ dysfunction syndrome (MODS), symmetrical peripheral gangrene $(\mathrm{SPG})$, and necrotizing soft tissue infection of the buttocks in the next 10 days. Authors used a series of debridement and reconstructive surgery including vacuum sealing drainage (VSD) treatment, artificial dermis grafts,split-thickness skin grafts, amputation surgeries when her vital signs were stable. The patient experienced desquamation of the hand on the 26th day. The skin grafts survived and the function of both fingers and toes recovered. She was discharged 2 months after admission and was in good health.
\end{abstract}

Conclusion: TSS is extremely rare in the field of liposuction and autologous fat transfer. The mortality rate of TSS is very high. Early diagnosis and operative treatment, as well as correction of systemic abnormalities, are the important keys to save a patient's life.

Keywords: Liposuction, Toxic shock syndrome, Multiple organ dysfunction syndrome, Necrotizing soft tissue infection, Symmetrical peripheral gangrene

\section{Background}

With more and more people pursuing the beauty of body shape, liposuction and autologous fat transplantation have become one of the most commonly used cosmetic

\footnotetext{
*Correspondence: drzxh@qq.com

${ }^{\dagger}$ Zhiwan Liu, Wenjun Zhang and Boyu Zhang authors contributed equally to this work

${ }^{1}$ Department of Plastic Surgery, Shanghai Changzheng Hospital, No.415 Fengyang Road, Huangpu District, Shanghai 200003, China

Full list of author information is available at the end of the article
}

surgery in the world [1]. The common complications of liposuction include seroma, hematoma, infection, lymphoedema, hyperpigmentation, asymmetry [2, 3]. Lethal complications include necrotizing fasciitis, TSS, fat embolism syndrome, and even death [4-6]. However, most plastic surgeons and patients do not know much about the possible complications or comorbidities that may accompany such a procedure.

TSS was first described by Todd and co-workers in 1978 [7]. It can rapidly progress to shock and multiorgan 
failure. TSS is associated with postoperative wound infections that can occur in postoperative patients, in the previous reports the incidence of postoperative wound infection was very low if following clean elective procedures [8, 9]. 40-60\% TSS is caused by Staphylococcus aureus, which presenting symptoms include high fever, diarrhea, nausea, a diffuse macular rash, and desquamation. Besides, most cases are reported to involve cosmetic plastic surgery such as chemical peeling, breast augmentation, rhinoplasty with and without nasal packing, abdominoplasty, and liposuction. SPG is defined as two or more limb ischemia injuries, no large vessel obstruction, or vasculitis. SPG is a rare but severe complication of DIC and is frequently associated with sepsis, which is $85 \%$ of the SPG caused by DIC [10]. SPG results in high rates of amputation and mortality; in particular, amputation is a serious problem for survivors $[11,12]$.

The incidence rate of TSS with SPG after liposuction and autologous fat transfer is extremely low, and there is no case was been reported worldwide, including in China. Here, we presented a young girl with TSS who experienced MODS, DIC, and SPG after liposuction and autologous fat transfer.

\section{Case presentation}

\section{Case}

A 23-year-old girl underwent liposuction of the thighs and extensive autologous fat transfer of buttocks, breasts, and face on 7 October 2020. $6 \mathrm{~h}$ after the operation, she had a high fever, hypotension, chills, vomiting, and bilateral thigh bleeding. The patient was thereafter admitted to our emergency room at night. On physical examination, her body temperature was $39.7^{\circ} \mathrm{C}$, heart rate was 135 beats/minute, and blood pressure was $83 / 39 \mathrm{mmHg}$. Several small scattered incisions from the liposuction and lipotransfer process were observed in the thighs, buttocks, breasts, and face. Besides, petechial skin lesions on the region of the back, lumbosacral, buttocks, posterior thighs with swelling and tenderness, and diffusely distributed erythematous lesions appeared at her toes and hands.

The patient's laboratory data were notable for a white cell count (WBC) of $2.8 \times 10^{9}$ cells/ $\mathrm{L}$ (normal:3.5-9.5 $\left.\times 10^{9} / \mathrm{L}\right)$, hemoglobin $49 \mathrm{~g} / \mathrm{L}$ (normal:115-150 g/L), and decreased platelets at $49 \times 10^{9}$ cells/L(normal:125-350 $\times 10^{9} / \mathrm{L}$,). Blood coagulation studies revealed prothrombin time (PT) of $34.2 \mathrm{~s}$ (normal:9.8-12.1 s), activated partial thromboplastin time (APTT) of $131.6 \mathrm{~s}$ (normal:22.7-31.8 s), international normalized ratio (INR) 3.38(normal:0.79-1.14), D-dimers $70.40 \mathrm{ug} / \mathrm{ml}$ (normal: $<0.55 \mathrm{ug} /$ $\mathrm{mL}$ ), fibrinogen level was undetectable. Her potassium was $2.86 \mathrm{mmol} / \mathrm{L}$ (normal: $3.5-5.5 \mathrm{mmol} / \mathrm{L}$ ), calcium was
$1.57 \mathrm{mmol} / \mathrm{L}$ (normal: $2.25-2.75 \mathrm{mmol} / \mathrm{L}$ ) and serum creatinine was $101 \mathrm{umol} / \mathrm{L}$ (normal:46-92 umol/L). Liver function tests demonstrated albumin level was $13.5 \mathrm{~g} / \mathrm{L}$ (normal:63.0-82.0 g/L); the total bilirubin level was $87.2 \mu \mathrm{mol} / \mathrm{L}$ (normal:2.0-22.0 $\mu \mathrm{mol} / \mathrm{L}$ ); the serum lactate level was $8.1 \mathrm{mmol} / \mathrm{L}$ (normal:0.5-1.6 mmol/L); the creatine kinase (CK) level was $918 \mathrm{U} / \mathrm{L}$ (normal:30135U/L), myocardial-bound creatine kinase (CK-MB) was $17 \mathrm{U} / \mathrm{L}($ normal:0-16U/L), muscle-type creatine kinase (CK-MM) was 901U/L(normal:0-137U/L)). An arterial blood gas analysis showed a potential of hydrogen $(\mathrm{PH})$ of 7.37 , a partial pressure of oxygen $\left(\mathrm{PO}_{2}\right)$ of $165 \mathrm{mmHg}$, and a Partial Pressure of Carbon Dioxide $\left(\mathrm{PCO}_{2}\right)$ of $29 \mathrm{mmHg}$. Cultures of blood, stool, and urine obtained before antibiotic therapy were negative.

She was additionally treated with vancomycin and imipenem, blood transfusion, massive fluid resuscitation, and a series of supportive therapy. During the next day, the patient's condition worsened, a chest $\mathrm{x}$-ray film showed massive infiltrations in both lungs. She was immediately admitted to the intensive care unit (ICU) and treated with continuous pumps of norepinephrine and metaraminol, imipenem, and vancomycin as empiric anti-infective, blood transfusions. On the second day after admission, the patient's condition deteriorated, and each test indicator continued to higher or lower than the normal range; CT showed pneumonia, pleural effusion, and gastric retention, and blood gas analysis suggested severe metabolic acidosis. Gastrointestinal decompression tube drainage gives about $1500 \mathrm{ml}$ brown liquid.

She was in a state of persistent hyperthermia that her body temperature peaked at $40.1^{\circ} \mathrm{C}$; On the third night after admission, the patient developed rapid heart rate ( 144 beats/min), shortness of breath ( 25 beats $/ \mathrm{min}$ ), and confusion; blood gas analysis indicated $\mathrm{PH} 7.31, \mathrm{PCO}_{2}$ $50 \mathrm{mmHg}, \mathrm{PO}_{2} 43 \mathrm{mmHg}$, lactate $3.5 \mathrm{mmol} / \mathrm{L}$, blood oxygen saturation $\left(\mathrm{SpO}_{2}\right) 73 \%$. Additionally, the patient's urine was dark brown, and a large amount of exudation was drained from both thighs. Endotracheal intubation was performed with ventilator-assisted ventilation. On the 7th day after admission, bedside hemodialysis was performed because the patient's urine color continued to become dark, $\mathrm{CK}-\mathrm{MB}$, myoglobin, and infection indicators (C-reaction protein [CRP], Procalcitonin [PCT]) continued to rise. During the first 3 weeks after admission, a total of $3600 \mathrm{~mL}$ red blood cells, $1200 \mathrm{~mL}$ fresh frozen plasma, 4units $(\mathrm{U})$ of platelet concentrate, $42 \mathrm{U}$ of cryoprecipitate coagulation factor, and large amounts of human fibrinogen and prothrombin complexes were used. The patient has gradually improved after positive and effective treatment, and the test indicators have gradually returned to the normal range (Additional file 1, which demonstrates the changes of patient's body 
temperature and lab test indicators from day 1 through day 14 after admission).

Although the erythematous rush has subsided, peripheral ischemia appeared on her fingers and toes and gradually resulted in gangrene (Fig. 1). What's worse, her buttocks occurred necrotizing soft tissue infection. By the time her body was strong enough to withstand surgery and the gangrenous areas became demarcated, surgical amputation of fingers and toes gangrenous areas on the peripheral extremities was performed; both fingers and toes were secondly covered with split-thickness skin after firstly artificial dermis grafts; her buttocks were grafted with split-thickness skin after twice full debridement and treated with VSD (Fig. 2). During the period, antibiotics (vancomycin, imipenem, teicoplanin, tigecycline,
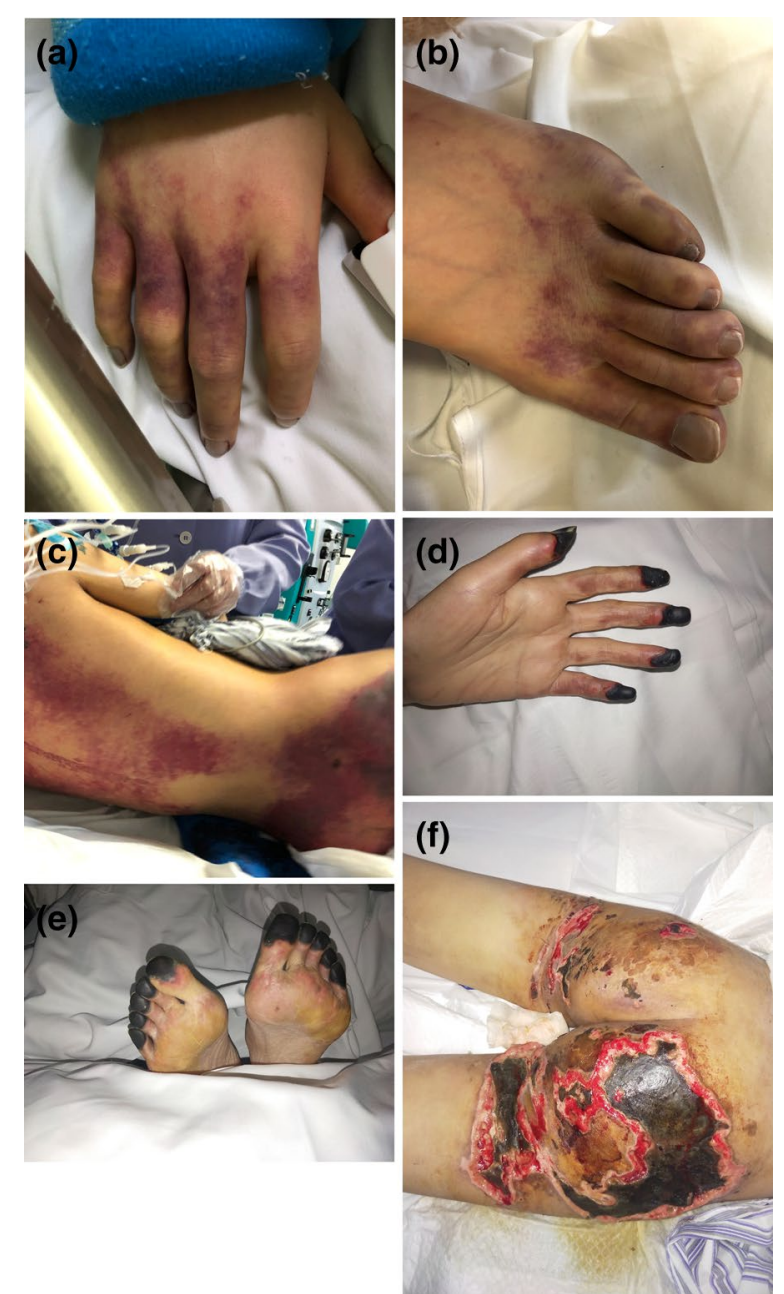

Fig. 1 Petechial skin lesions appeared on her hands (A), toes (B), lumbosacral $(\mathbf{C})$, buttocks $(\mathbf{C})$, and posterior thighs $(\mathbf{C})$ on the first day. Symmetrical peripheral gangrene of her fingers $(\mathbf{D})$, toes $(\mathbf{E})$, and necrotizing soft tissue infection on her buttocks (F) on hospital day 26

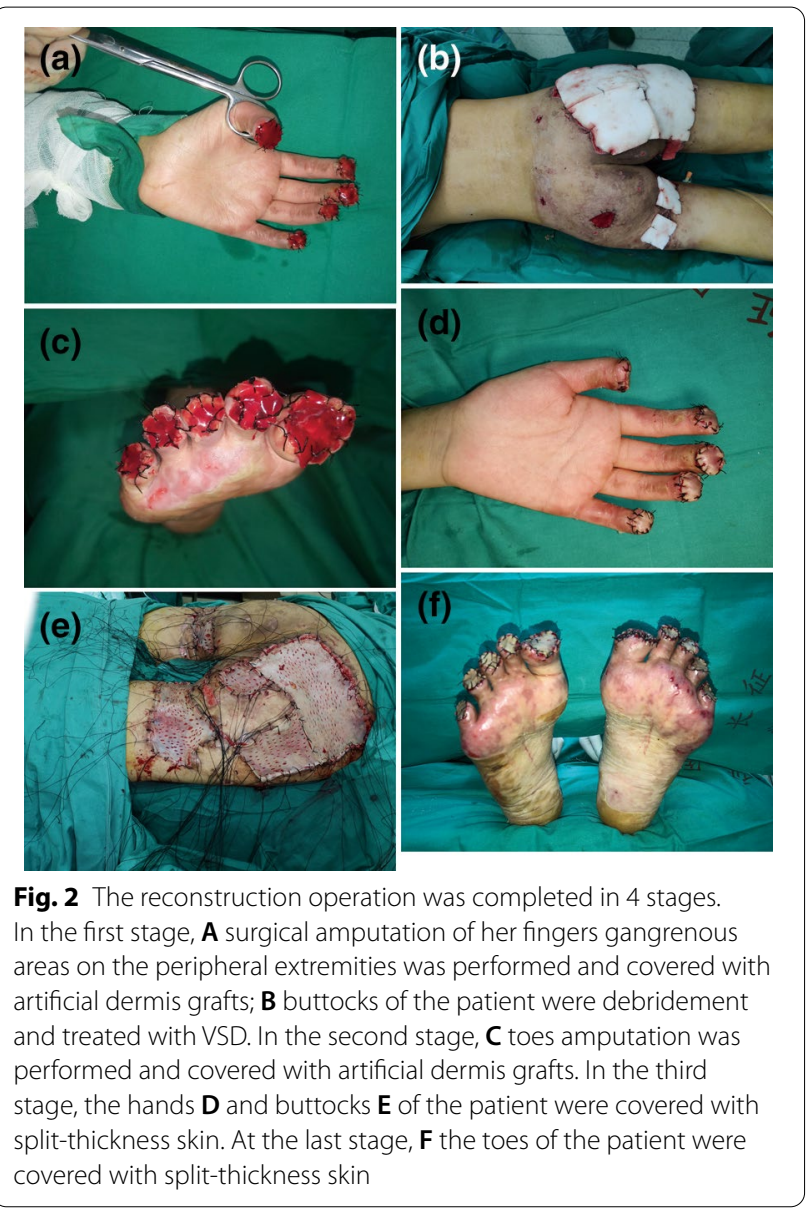

sulperazone, polymyxin, Linezolid, phosphonomycin) and antifungal drugs (Caspofungin, Fluconazole) were replaced according to the patient's sputum culture, wound secretion culture, and drug sensitivity.

Blood cultures were persistently negative for the growth of organisms, but Candida tropicalis was identified by the untargeted next-generation sequencing of sputum; Klebsiella pneumonia was identified by the untargeted next-generation sequencing of blood; Acinetobacter baumannii, Proteus mirabilis, and Klebsiella pneumonia were detected in the buttock subcutaneous effusion culture. The patient experienced desquamation of the hand on the 26th day after admission (Fig. 3). The skin grafts survived and the function of both fingers and toes recovered well. She was discharged 2 months after admission and was in good health at the last follow-up (Fig. 4).

\section{Discussion and conclusions}

Liposuction and autologous fat transfer are the most commonly performed cosmetic surgeries over worldwide. Most plastic surgeons and patients neglect its 


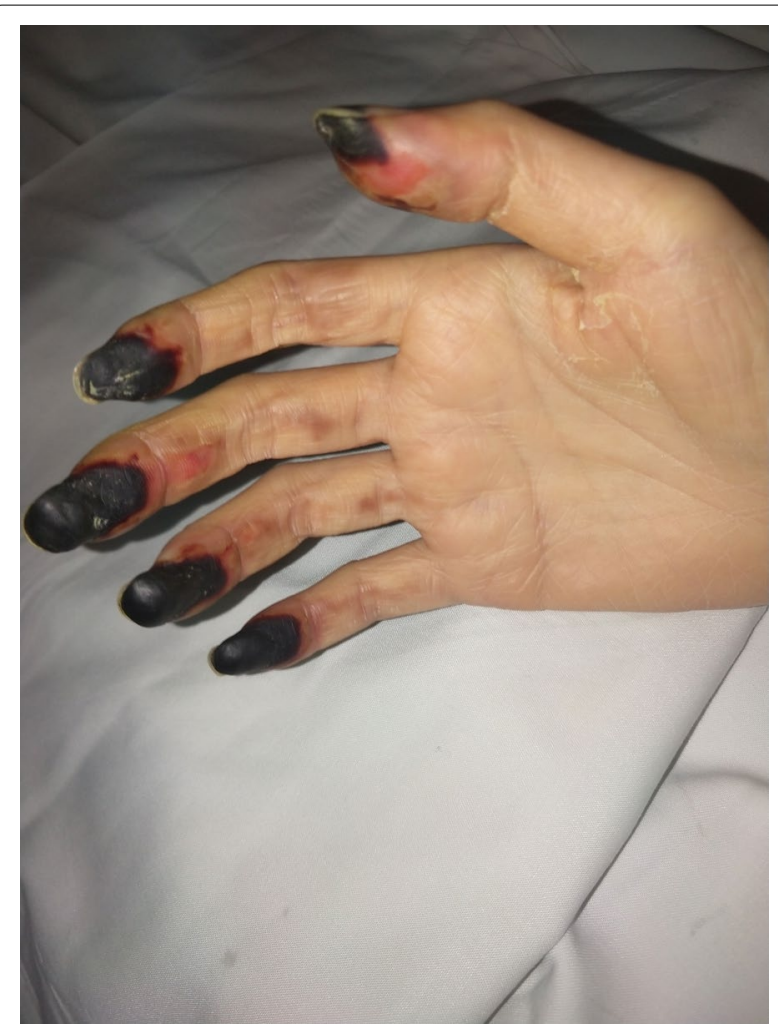

Fig. 3 Desquamations of the patient's hands were observed on hospital day 26

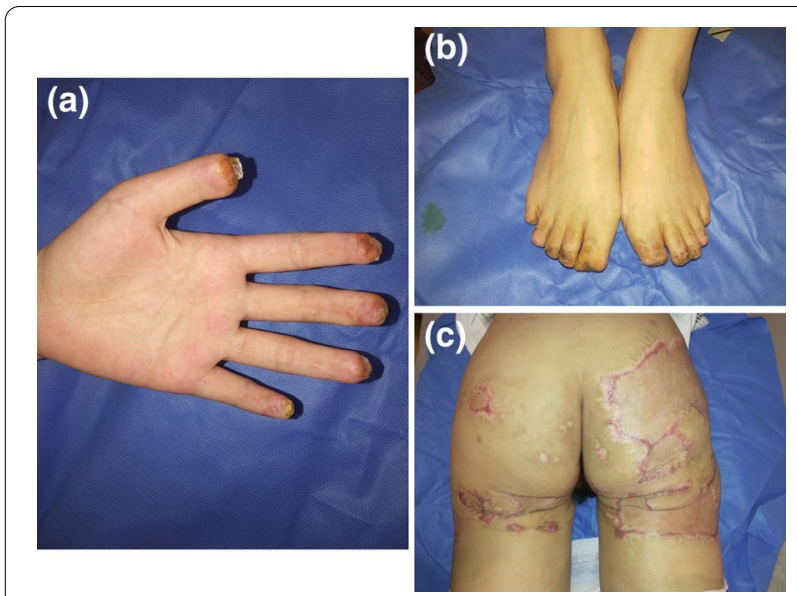

Fig. 4 At the last follow-up after 4 months the hand (A), toes (B), and buttocks $(\mathbf{C})$ of the patient were improved significantly

dangers, which the common clinic complications just include slight infection, bleeding, hematoma, seroma, and lymphoedema $[2,3]$. However, that is not the case. As with any surgical procedure, liposuction still imparts potential morbidity and mortality. Major potentially life-threatening complications of liposuction include necrotizing fasciitis, TSS, pulmonary embolism, toxicity or drug interactions, and visceral organ perforation $[4-6,13]$. TSS and necrosis fasciitis commonly are severe infections. Compared with the common postoperative complications after liposuction, TSS is very rare and relatively unknown to most plastic surgeons. During the past 30 years, only a few pieces of literature on TSS associated with liposuction have been reported [14-17]. TSS is a life-threatening infection characterized by a rapid progression of the disease. Since patients undergoing cosmetic surgery are basically healthy and demanding, any kind of fatal complication was hard to be accepted.

TSS is a multi-system, life-threatening disease, mainly caused by superantigen toxin-producing strains of Staphylococcus aureus and Streptococcus pyogenes [18-20]. Its clinical manifestation includes high fever, rash, vomiting, diarrhea, and multiple organ failure. The circumstances that cause TSS are more complex. Bacteria are the most common causative agents underlying postoperative TSS. Staphylococcus aureus, S epidermidis, Streptococci A and B, Streptococcus pyogenes, Klebsiella pneumonia, Bacillus are most often implicated. Corynebacterium, Pseudomonas aeruginosa, Escherichia coli, and Enterobacteriaceae are also occasionally implicated [9, 14, 21-29]. In the last few decades, TSS has been mainly associated with menstruating women who use intravaginal tampons [19, 30]. But with the rapid development of cosmetic surgeries, TSS has been observed a trend in increasing frequency in plastic surgical patients [31, 32].

The clinical diagnosis of TSS is based on a series of signs and symptoms, meanwhile, other diseases and causes that could lead to a septic shock-like state need to be excluded. The differences between TSS and common postoperative wound infections include a short incubation period, the rapid development of multiple system organ failures, and a series of dermatologic manifestations, requiring large amounts of fluid resuscitation and vasopressor to maintain blood pressure [8].

The constellation of our patient's symptoms met with the TSS 2011 Case Definition by the Centers for Disease Control and Prevention. According to the standards supported by the Centers for Disease Control and Prevention in 2011 (Additional file 2, which provides detailed diagnostic criteria for TSS) [33], an obvious feature of postoperative TSS(Other Than Streptococcal) is that signs of local wound infection rarely occur. Blood, urine, and throat cultures are characteristically negative. Positive blood culture results are rare in staphylococcal TSS with less than $5 \%$ positive [1]. Despite a high fever and markedly increased white blood cell count, CRP, and PCT suggesting severe infection, the patient's blood culture results were consistently negative. 
When we reviewed the previous literature, we found that this is might be the second reported case of SPG associated with TSS. The first case of SPG complicating TSS occurred in a young woman who is in lactation, she just experienced abortion surgery two months ago [34]. But our case might be the first case report of SPG associated with TSS in the field of plastic surgery. Most SPG relates to the use of vasopressors with DIC [35, 36]. Hypotension due to sepsis is another suspected cause of SPG and is thought to be aggravated by the administration of hypotensive therapy [37]. There are no reports of SPG as sequelae of DIC in the setting of TSS. Intravascular thrombosis and infarction of the skin and distal extremities can be caused by DIC. The resulting low blood flow state can lead to thrombus occlusion of the microcirculation of the affected limb extremities [10]. The characteristics of SPG are symmetric necrosis of the skin and distal extremities, followed by gangrene in two or more distal sites without occlusion of the great arteries. About $18-40 \%$ mortality rate was reported, and survivors have a high frequency of multiple limb amputations [38]. Early amputation is contraindicated because secondary infection of necrotic tissue is uncommon and the boundaries of ischemic lesions occur over time [39]. No treatment has proved to be completely effective, so identifying and treating the underlying cause helps to arrest and prevent further progression in SPG [40]. Early recognition remains the key factor in SPG management.

In conclusion, early identification and timely treatment is the best way to reduce the mortality and sequelae of TSS. Controlling the source of infection through surgical debridement and abscess drainage is the first choice for initial and continuous treatment. When TSS is suspected, active fluid resuscitation, antibiotic treatment, and intensive care support should be taken immediately even if the patient has no signs of local infection. In addition, most of the patients who seek plastic surgery are healthy people who want to be better than before, but such serious complications are difficult for them and their families to accept. Therefore, it requires us to not only have a deep understanding of the occurrence and treatment of postoperative complications but also strictly abide by the principles of aseptic operation during the surgical operation.

\footnotetext{
Abbreviations

TSS: Toxic Shock Syndrome; DIC: Disseminated Intravascular Coagulation; MODS: Multiple Organ Dysfunction syndrome; SPG: Symmetrical Peripheral Gangrene; VSD: Vacuum Sealing Drainage; WBC: White cell count; PT: Prothrombin time; APTT: Activated partial thromboplastin time; INR: International normalized ratio; CK: Creatine Kinase; CK-MB: Myocardial-Bound Creatine Kinase; CK-MM: Muscle-type Creatine Kinase; $\mathrm{PH}$ : Potential of Hydrogen; $\mathrm{PO}_{2}$ : : Partial Pressure of Oxygen; $\mathrm{PCO}_{2}$ : Partial Pressure of Carbon Dioxide; $\mathrm{SpO} 2$ : Oxygen saturation; ICU: Intensive Care Unit; CRP: C-reaction protein; PCT: Procalcitonin; U: Units.
}

\section{Supplementary Information}

The online version contains supplementary material available at https://doi. org/10.1186/s12879-021-06777-2.

Additional file 1: Body temperature and laboratory parameters from day 1 to day 14 after admission.

Additional file 2: Centers for Disease Control and Prevention TSS (Other Than Streptococcal) Diagnostic Criteria.

\section{Acknowledgements \\ I would like to thank my fellow co-authors for their hard work, support, guid- ance, and contributions.}

\section{Authors' contributions}

LZW and ZWJ: conceptualization. LZW, ZBY and GH: pertinent information collection of the patient. HZY, JX, MLH, ZF, GH, ZWJ, and ZXH: clinical check and treatment of the patient. LZW, ZWJ, and ZBY: writing of original draft. ZXH and ZWJ: supervision, writing - review \& editing. All authors reviewed the draft critically, approved the final version to be submitted, and take accountability for all aspects of the typescript. All authors read and approved the final manuscript.

\section{Funding}

None.

\section{Availability of data and materials}

The datasets used and/or analysed during the current study are available from the corresponding author on reasonable request.

\section{Declarations}

Ethics approval and consent to participate Not applicable.

\section{Consent to publication}

Written informed consent was obtained from the patient for publication of this Case report and any accompanying images. A copy of the consent form is available for review by the Editor of this journal.

\section{Competing interests}

Authors received no honoraria, grants, or other payments for writing this manuscript. In addition, the authors report no relevant financial relationships and no conflicts of interest.

\section{Author details}

${ }^{1}$ Department of Plastic Surgery, Shanghai Changzheng Hospital, No.415 Fengyang Road, Huangpu District, Shanghai 200003, China. ${ }^{2}$ Department of Emergency, Shanghai Changzheng Hospital, Shanghai, China. ${ }^{3}$ Department of Plastic Surgery, Shanghai Tongji Hospital, Shanghai, China.

Received: 13 May 2021 Accepted: 8 October 2021

Published online: 06 November 2021

References

1. Montrief T, Bornstein K, Ramzy M, Koyfman A, Long BJ. Plastic surgery complications: a review for emergency clinicians. West J Emerg Med. 2020;21(6):179-89. https://doi.org/10.5811/westjem.2020.6.46415.

2. Kim YH, Cha SM, Naidu S, Hwang WJ. Analysis of postoperative complications for superficial liposuction: a review of 2398 cases. Plast Reconstr Surg. 2011;127(2):863-71. https://doi.org/10.1097/PRS.0b013e318200afbf.

3. Stephan PJ, Kenkel JM. Updates and advances in liposuction. Aesthet Surg J. 2010;30(1):83-97. https://doi.org/10.1177/1090820X10362728.

4. Grazer FM, de Jong RH. Fatal outcomes from liposuction: census survey of cosmetic surgeons. Plast Reconstr Surg. 2000;105(1):436-46. https://doi. org/10.1097/00006534-200001000-00070. 
5. Ezzeddine H, Husari A, Nassar H, Kanso M, Nounou GE, Khalife M, et al. Life threatening complications post-liposuction. Aesthetic Plast Surg. 2018;42(2):384-7. https://doi.org/10.1007/s00266-017-1058-x.

6. Lehnhardt M, Homann HH, Daigeler A, Hauser J, Palka P, Steinau HU. Major and lethal complications of liposuction: a review of 72 cases in Germany between 1998 and 2002. Plast Reconstr Surg. 2008;121(6):396e-403e. https://doi.org/10.1097/PRS.0b013e318170817a.

7. Todd J, Fishaut M, Kapral F, Welch T. Toxic-shock syndrome associated with phage-group-I Staphylococci. Lancet. 1978;2(8100):1116-8. https:// doi.org/10.1016/s0140-6736(78)92274-2

8. Graham DR, O'Brien M, Hayes JM, Raab MG. Postoperative toxic shock syndrome. Clin Infect Dis. 1995;20(4):895-9. https://doi.org/10.1093/clini ds/20.4.895.

9. Reingold AL, Dan BB, Shands KN, Broome CV. Toxic-shock syndrome not associated with menstruation. A review of 54 cases. Lancet. 1982;1 (8262):1-4. https://doi.org/10.1016/s0140-6736(82)92552-1.

10. Shimbo K, Yokota K, Miyamoto J, Okuhara Y, Ochi M. Symmetrical peripheral gangrene caused by septic shock. Case Rep Plast Surg Hand Surg. 2015;2(3-4):53-6. https://doi.org/10.3109/23320885.2015.1041529.

11. Goodwin JN. Symmetrical peripheral gangrene. Arch Surg. 1974;108(6):780-4. https://doi.org/10.1001/archsurg.1974.0135030002 2006.

12. Molos MA, Hall JC. Symmetrical peripheral gangrene and disseminated intravascular coagulation. Arch Dermatol. 1985;121(8):1057-61.

13. You JS, Chung YE, Baek SE, Chung SP, Kim MJ. Imaging findings of liposuction with an emphasis on postsurgical complications. Korean J Radiol. 2015;16(6):1197-206. https://doi.org/10.3348/kjr.2015.16.6.1197.

14. Rhee CA, Smith RJ, Jackson IT. Toxic shock syndrome associated with suction-assisted lipectomy. Aesthetic Plast Surg. 1994;18(2):161-3. https://doi.org/10.1007/BF00454477.

15. Bell MS, Doherty GP, Gutauskas A. Liposuction sepsis—be alert. Can J Plast Surg. 2009;17(4):e29-32.

16. Vongpaisarnsin $\mathrm{K}$, Tansrisawad N, Hoonwijit U, Jongsakul T. Pseudomonas aeruginosa septicemia causes death following liposuction with allogenic fat transfer and gluteal augmentation. Int J Legal Med. 2015;129(4):815-8. https://doi.org/10.1007/s00414-014-1056-3.

17. De la Fuente JRO, Ferdinand A, Dybas M, Montrief T, Cabrera J. Necrotizing soft tissue infection and perforated viscus after suction-assisted lipectomy. Cureus. 2020;12(6):e8617. https://doi.org/10.7759/cureus.8617.

18. Wilkins AL, Steer AC, Smeesters PR, Curtis N. Toxic shock syndromethe seven Rs of management and treatment. J Infect. 2017;74(Suppl 1):S147-52. https://doi.org/10.1016/S0163-4453(17)30206-2.

19. Jarrahy R, Roostaeian J, Kaufman MR, Crisera C, Festekjian JH. A rare case of staphylococcal toxic shock syndrome after abdominoplasty. Aesthet Surg J. 2007;27(2):162-6. https://doi.org/10.1016/j.asj.2007.01.007.

20. Gottlieb M, Long B, Koyfman A. The evaluation and management of toxic shock syndrome in the emergency department: a review of the literature. J Emerg Med. 2018;54(6):807-14. https://doi.org/10.1016/j.jemermed. 2017.12.048.

21. Tang WM, Ho PL, Yau WP, Wong JW, Yip DK. Report of 2 fatal cases of adult necrotizing fasciitis and toxic shock syndrome caused by Streptococcus agalactiae. Clin Infect Dis. 2000;31(4):E15-17. https://doi.org/10.1086/ 318148 .

22. Sims KD, Barton TD. Group B streptococcal toxic shock syndrome in an asplenic patient: case report and literature review. Eur J Clin Microbiol Infect Dis. 2006;25(3):208-10. https://doi.org/10.1007/s10096-006-0106-2.

23. Ikebe T, Chiba K, Shima T, Masuda C, Okuno R, Ohya H, et al. Evaluation of streptococcal toxic shock-like syndrome caused by group B streptococcus in adults in Japan between 2009 and 2013. J Infect Chemother. 2015;21(3):207-11. https://doi.org/10.1016/j.jiac.2014.12.002.

24. Yoshida M, Takazono T, Tashiro M, Saijo T, Morinaga Y, Yamamoto K, et al. Recurrent Streptococcus agalactiae toxic shock syndrome triggered by a tumor necrosis factor-alpha inhibitor. Intern Med. 2016;55(21):3211-4. https://doi.org/10.2169/internalmedicine.55.6787.
25. Young K, Luni FK, Yoon Y. Toxic shock syndrome: an unusual organism. Am J Med Sci. 2016;352(1):86-90. https://doi.org/10.1016/j.amjms.2016. 04.002.

26. Madhusudhan TR, Sambamurthy S, Williams E, Smith IC. Surviving streptococcal toxic shock syndrome: a case report. J Med Case Rep. 2007;1:118. https://doi.org/10.1186/1752-1947-1-118.

27. Korman TM, Boers A, Gooding TM, Curtis N, Visvanathan K. Fatal case of toxic shock-like syndrome due to group C streptococcus associated with superantigen exotoxin. J Clin Microbiol. 2004;42(6):2866-9. https://doi. org/10.1128/JCM.42.6.2866-2869.2004.

28. Baxter M, Morgan M. Streptococcal toxic shock syndrome caused by group G streptococcus United Kingdom. Emerg Infect Dis. 2017;23(1):127-9. https://doi.org/10.3201/eid2301.161009.

29. Sinave C, Le Templier G, Blouin D, Leveille F, Deland E. Toxic shock syndrome due to Clostridium sordellii: a dramatic postpartum and postabortion disease. Clin Infect Dis. 2002;35(11):1441-3. https://doi.org/10.1086/ 344464.

30. Shands KN, Schmid GP, Dan BB, Blum D, Guidotti RJ, Hargrett NT, et al. Toxic-shock syndrome in menstruating women: association with tampon use and Staphylococcus aureus and clinical features in 52 cases. N Engl J Med. 1980;303(25):1436-42. https://doi.org/10.1056/NEJM19801218303 2502.

31. Hisanaga K, Kadota H, Fukushima S, Inatomi Y, Shimamoto R, Kamizono $K$, et al. Toxic shock syndrome caused by staphylococcal infection after breast implant surgery: a case report and literature review. Ann Plast Surg. 2019;83(3):359-62. https://doi.org/10.1097/SAP.0000000000001868.

32. Bresler MJ. Toxic shock syndrome due to occult postoperative wound infection. West J Med. 1983;139(5):710-3.

33. Centers for Disease Control and Prevention. Toxic Shock Syndrome (Other Than Streptococcal) (TSS):2011 Case Definition. https://wwwn.cdc.gov/ nndss/conditions/toxic-shock-syndrome-other-than-streptococcal/casedefinition/2011/.

34. Rai SP, Neog LS, Bhattacharyya D, Ganguli M. Symmetrical peripheral gangrene complicating staphylococcal toxic shock syndrome. Med J Armed Forces India. 2008;64(2):181-2. https://doi.org/10.1016/S0377-1237(08) 80076-7.

35. Ghosh SK, Bandyopadhyay D, Ghosh A. Symmetrical peripheral gangrene: a prospective study of 14 consecutive cases in a tertiary-care hospital in eastern India. J Eur Acad Dermatol Venereol. 2010;24(2):214-8. https:// doi.org/10.1111/j.1468-3083.2009.03329.x.

36. Shenoy R, Agarwal N, Goneppanavar U, Shenoy A, Sharma A. Symmetrical peripheral gangrene-a case report and brief review. Indian J Surg. 2013;75(Suppl 1):163-5. https://doi.org/10.1007/s12262-012-0576-7.

37. Uncu Ulu B, Yigenoglu TN, Hacibekiroglu T, Saglam DA, Kilinc A, Iskender $G$, et al. Recovery of symmetrical peripheral gangrene of limbs in a patient after performing hemoadsorption in septic shock. J Clin Apher. 2021;36(4):649-53. https://doi.org/10.1002/jca.21893.

38. Albano MN, Brazao SG, Caroco TV, Louro JM, Coelho Ml, Costa Almeida $\mathrm{CE}$, et al. Rare case of symmetrical peripheral gangrene due to septic shock, disseminated intravascular coagulation and inotropic use. Ann Med Surg (Lond). 2018;35:103-7. https://doi.org/10.1016/j.amsu.2018.09. 025.

39. Suarez-Amor O, Casado-Arroyo R, Cabanillas M, Labandeira J, Toribio J. Symmetrical peripheral gangrene and disseminated intravascular coagulation associated with pneumococcal sepsis. Actas Dermosifiliogr. 2009;100(4):334-5.

40. Jiang JL, Tseng LW, Chang HR. Symmetrical peripheral gangrene in sepsis after treatment with inotropes. Ci Ji Yi Xue Za Zhi. 2017;29(2):121-4. https://doi.org/10.4103/tcmj.tcmj_25_17.

\section{Publisher's Note}

Springer Nature remains neutral with regard to jurisdictional claims in published maps and institutional affiliations. 